\title{
Repair of a traumatic sternal deformity
}

Adel I. Irani, MD, Taek-Yeon Lee, MD, Anthony L. Estrera, MD, and Hazim J. Safi, MD, Houston, Tex

Acquired deformities of the anterior chest wall have been classified into groups. ${ }^{1}$ There are reports in the literature on the treatment of sternal dehiscence and nonunion after median sternotomy. A review of the English-language literature, however, found little about the treatment of sternal fractures after blunt trauma, because most such fractures are managed nonoperatively with low morbidity and mortality. We report a case of a chronic sternal fracture that healed in a severely angulated fashion, was associated with pain, and was treated with open reduction and fixation.

\section{CLINICAL SUMMARY}

Our patient was a 44-year-old woman involved in a rollover motor vehicle accident as the restrained driver on March 26, 2007. At presentation, she reported severe back pain. Radiologic examination revealed two nondisplaced sternal fractures, a third thoracic vertebral chip fracture, and a fourth thoracic vertebral burst fracture. The patient subsequently underwent open reduction and internal fixation of the second through sixth thoracic vertebrae by the neurosurgical service. Three days after that, she was taken back to the operating room for removal and repositioning of the right pedicle screws for proximity to the esophagus. She was discharged home with physical therapy on April 1, 2007. In July 2007, the patient was referred to the thoracic surgery clinic for anterior chest wall pain. Evaluation showed a marked anterior chest wall deformity consisting of a concave and convex displacement of the sternum, with the deformity confirmed by imaging. Subsequently, the patient was admitted for repair of her sternum.

At operation, the sternum was exposed through a midline skin incision, and small bilateral pectoralis flaps were raised. We found that the sternum was healed in a severely angulated position (Figure 1). A midline sternotomy was performed. With a modification of the techniques developed by Ravitch, ${ }^{2}$ wedge osteotomies of the proximal and distal angulated areas were performed. The fractured sternal halves were then fixed in the longitudinal axis with the Synthes (Synthes, Inc, West Chester, Pa) titanium sternal plating system. This was done by selecting two identical plates that

\footnotetext{
From the Department of Cardiothoracic and Vascular Surgery, University of Texas Health Science Center, Memorial Hermann Heart and Vascular Institute, Houston, Tex.

Received for publication Nov 1, 2007; accepted for publication Dec 4, 2007.

Address for reprints: Adel I. Irani, MD, Assistant Professor, 6410 Fannin, Suite 450,

Houston, TX 77030 (E-mail: Adel.I.Irani@uth.tmc.edu).

J Thorac Cardiovasc Surg 2008;136:1371-2

$0022-5223 / \$ 34.00$

Copyright (C) 2008 by The American Association for Thoracic Surgery

doi:10.1016/j.jtcvs.2007.12.081
}

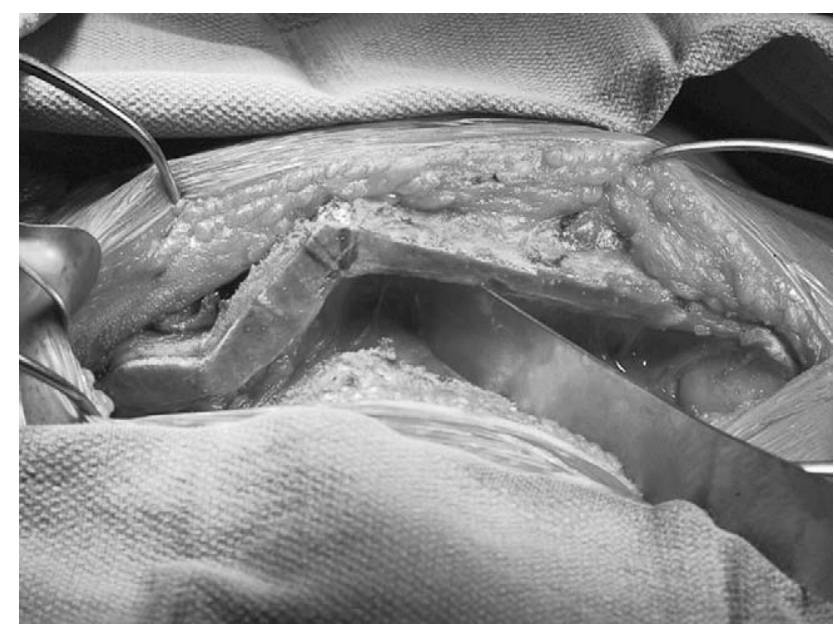

FIGURE 1. Angulated sternum.

were contoured in an anatomic fashion for rigid reconstruction. These plates were arranged in parallel on either side of the midline and were secured with bicortical titanium screws (Figure 2, A). The three sternal partitions were
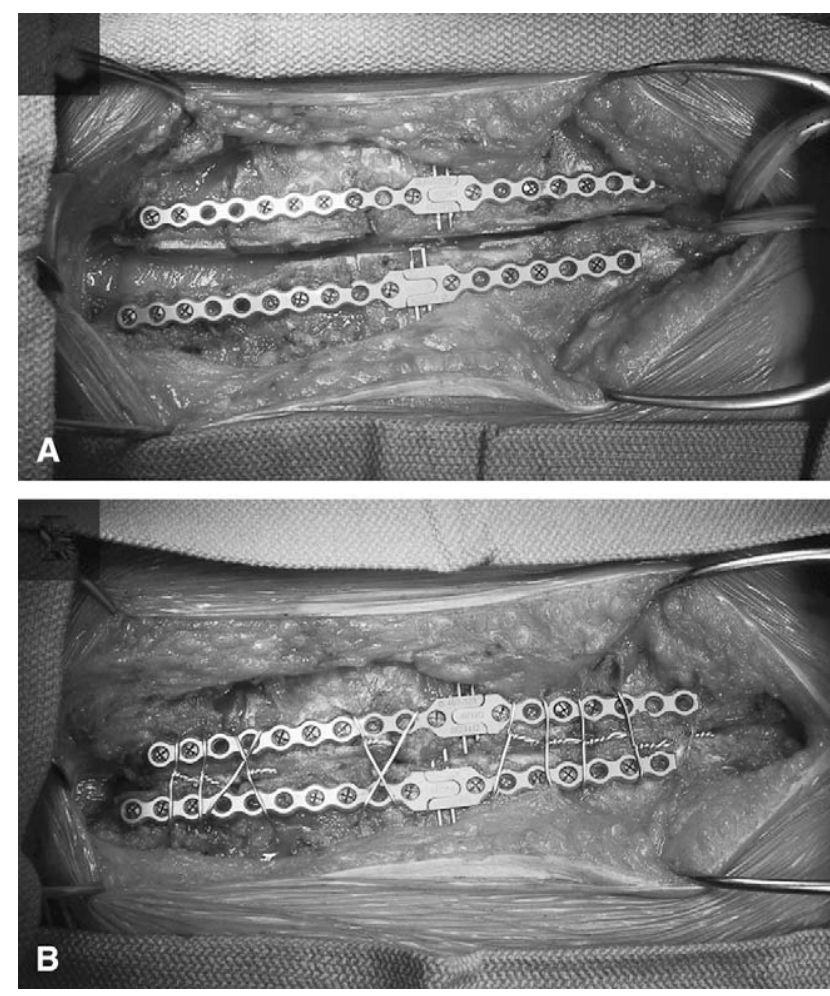

FIGURE 2. A, Sternal plates. B, Reapproximation of sternum. 
reapproximated with a tenaculum before rigid fixation on either side of the midline. The retrosternal structures were protected with a malleable retractor. The remaining defects at the areas of the osteotomies were packed with the bone from the initial portion of the procedure. The two halves of the sternum were then reapproximated with standard sternal wires, which were placed around the sternal plates (Figure $2, B)$. The patient's postoperative course was unremarkable, with resolution of the deformity, and she was discharged home in 4 days.

\section{DISCUSSION}

Most traumatic sternal fractures are treated nonoperatively, and only patients with fractures that are displaced or cause severe pain are operated on in the acute setting. This strategy was established by Richardson and colleagues ${ }^{3}$ with their report on 11 patients. Their management involved sternal fixation with wires, obviating sternal resection. In addition, they commented that dense scar present after a waiting period of just 1 week made the operation difficult. Bertin and associates ${ }^{4}$ described treatment of chronic sternal fractures with nonunion in 3 patients. Only 1 had a history of previous fracture. All were first seen with debilitating pain. The technique of Bertin and associates ${ }^{4}$ involved excision of the fracture site, rigid internal fixation with parallel plates, and bone grafting of the residual defect. Gallo and coworkers ${ }^{5}$ reported 1 case of a traumatic sternal fracture with chronic nonunion, again treated with plate fixation and iliac crest bone grafting. Our case, although similar, differs in that the patient's sternum had healed in a severely angulated position, causing debilitating pain and deformity. This case also differs in that iliac bone grafting was not necessary, so we were able to use our wedge osteotomy specimens as the graft. Because of the severe angulation of the healed sternum, an attempt at resection and repair without median sternotomy would bear unnecessary risk. We therefore used the technique of surgical débridement and rigid internal fixation with titanium plates with autologous bone grafting.

Chronic sternal fracture associated with debilitating pain and sternal deformity is an uncommon problem. It should be approached with the concepts of débridement of abnormal bone and rigid internal fixation. The use of large titanium plates and screws provides rigid fixation, allowing healing of the sternum.

\section{References}

1. Fokin AA, Robicsek F. Acquired deformities of the anterior chest wall. Thorac Cardiovasc Surg. 2006;54:57-61.

2. Ravitch M, Steichen F. Atlas of general thoracic surgery. Philadelphia: Saunders; 1988.

3. Richardson JD, Grover FL, Trinkle JK. Early operative management of isolated sternal fractures. J Trauma. 1975;15:156-8.

4. Bertin KC, Rice RS, Doty DB, Jones KW. Repair of transverse sternal nonunions using metal plates and autogenous bone graft. Ann Thorac Surg. 2002;73:1661-2.

5. Gallo DR, Lett ED, Conner WC. Surgical repair of a chronic traumatic sternal fracture. Ann Thorac Surg. 2006;81:726-8.

\title{
Pumpless extracorporeal gas exchange aiding central airway surgery
}

\author{
Thorsten Walles, MD, ${ }^{\mathrm{a}}$ Volker Steger, MD, ${ }^{\mathrm{a}}$ Holger Wurst, MD, ${ }^{\mathrm{b}}$ Klaus-Dieter Schmidt, MD, ${ }^{\mathrm{b}}$ and Godehard Friedel, MD, ${ }^{\mathrm{a}}$ \\ Gerlingen, Germany
}

In the setting of tracheobronchial resection and reconstruction, skilled coordination between surgeons and anesthesiologists is mandatory. However, tubing lines traversing the operating field, splashing liquids caused by tracheal gas flows, and thoracic excursions caused by artificial ventilation complicate the surgical procedure, especially when microsurgical techniques are applied. ${ }^{1}$ Therefore, during

From the Departments of Thoracic Surgery ${ }^{\mathrm{a}}$ and Anesthesiology, ${ }^{\mathrm{b}}$ Schillerhöhe Hospital, Gerlingen, Germany.

Received for publication Nov 4, 2007; accepted for publication Dec 24, 2007.

Address for reprints: Thorsten Walles, MD, Department of Thoracic Surgery, Schillerhöhe Hospital, Solitudestrasse 18, D-70839 Gerlingen, Germany (E-mail: twalles@ yahoo.com).

J Thorac Cardiovasc Surg 2008;136:1372-4

$0022-5223 / \$ 34.00$

Copyright $@ 2008$ by The American Association for Thoracic Surgery doi:10.1016/j.jtcvs.2007.12.092 surgery pulmonary ventilation may be replaced temporarily by alternative oxygenation techniques that are limited by the rise in arterial partial pressure of carbon dioxide $\left(\mathrm{PaCO}_{2}\right)^{2}$ The development of a new generation of low-resistance oxygenator membranes paved the way for pumpless extracorporeal lung assist (pECLA) devices that operate without expensive equipment and the expenses for trained staff. ${ }^{3}$ Because of our clinical pECLA experience in patients with acute lung failure, we applied this technology intraoperatively to afford the reconstruction of an extensive tracheoesophageal defect.

\section{CLINICAL SUMMARY}

A 63-year-old man was admitted for defect closure of an extensive esophagotracheal defect that had developed 